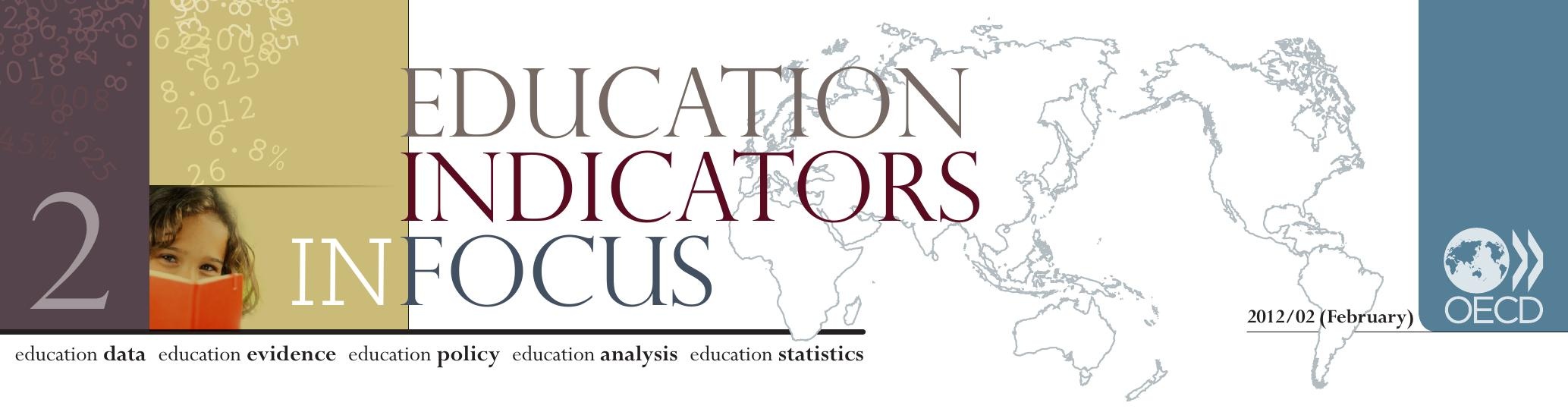

\title{
How are countries around the world supporting students in higher education?
}

- OECD countries in which students can benefit from sizeable financial support have above-average levels of access to university-level education, even when tuition fees are comparatively high.

- Student financial support systems that offer loans with income-contingent repayment to all students combined with means-tested grants can be an effective way to promote access and equity while sharing the costs of higher education between the state and students.

- An increasing number of OECD countries are charging higher tuition fees for international students, and many also differentiate them by field of study.

Tuition-fee structures and systems of student support vary widely across $O E C D$ countries.

When it comes to higher (tertiary) education, many countries have similar goals, such as strengthening the knowledge economy, increasing access for students, encouraging high completion rates, and assuring the financial stability of their higher education systems. Yet OECD countries differ dramatically in how the cost of higher education is structured - and in the financial support they provide to students.

\section{Average tuition fees vs. the percentage of students receiving public subsidies} for higher education, 2008-09

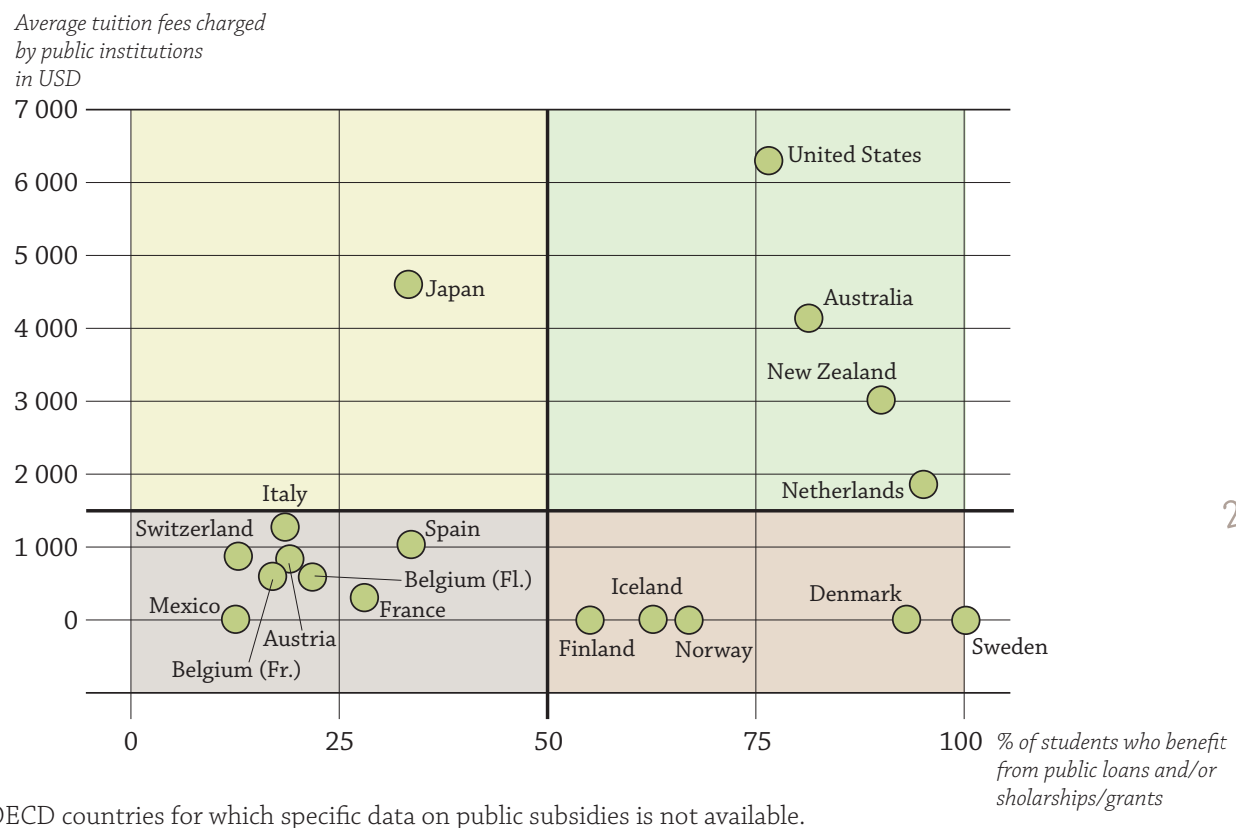

Note: Chart excludes OECD countries for which specific data on public subsidies is not available. sholarships/grants

Source: Education at a Glance 2011: OECD Indicators, Indicator B5 (www.oecd.org/edu/eag2011). 
For example, in countries with more progressive tax structures, such as Denmark, Finland, Iceland, Norway and Sweden, students pay low or no tuition fees and have access to generous public subsidies for higher education, but face high income tax rates. By contrast, tuition fees can be much higher in Australia, Canada, New Zealand, the Netherlands and the United States, though students in these countries also have access to significant financial support. Before recent reforms in Japan and in Korea, students paid comparatively high tuition fees, but had relatively low access to public subsidies. Meanwhile, in Austria, Belgium, the Czech Republic, France, Ireland, Italy, Portugal, Switzerland, Spain and Mexico, students pay little or nothing for higher education, but have limited access to financial aid.

At a time when most OECD countries are grappling with the twin challenges of ballooning higher education enrolments and constrained budgets, how well are these approaches enabling countries' higher education systems to achieve their key goals?

\section{In many countries, a well-developed student financial support system is vital} to achieving key outcomes...

OECD research suggests that charging a moderate level of tuition fees - while simultaneously giving students opportunities to benefit from comprehensive financial aid systems - is an effective way for countries to increase access to higher education, make efficient use of limited public funds, and acknowledge the significant private returns that students receive from higher education. While what constitutes "moderate" is not easy to define, OECD countries that charge for higher education most commonly have average annual tuition fees ranging from USD 800 to 1300 per year for full-time national students enrolled in university-level programmes. Many factors influence higher education entry rates, such as the quality of a country's primary and secondary education systems, the prevalence of vocational programmes, and the number of international students in the country's higher education system.

\section{Entry rates into university-level education}

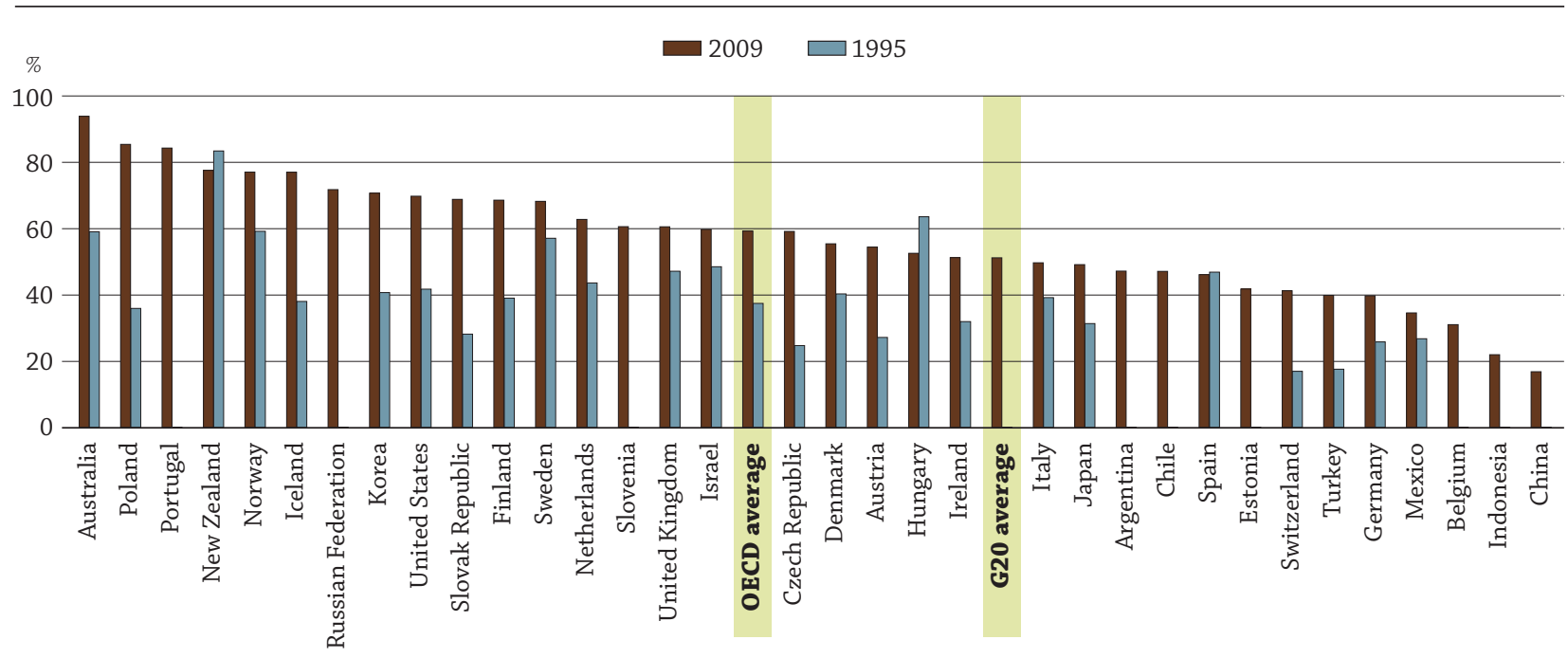

This figure shows the estimated percentage of today's young people who will enter a university-level programme at some point in their lifetime. Note: 2009 entry rates for the United States also include students not in university-level programmes.

Source: Education at a Glance 2011: OECD Indicators, Indicator C2 (www.oecd.org/edu/eag2011). 
However, it's worth noting that countries with particularly well-developed financial aid systems - such as Australia, New Zealand, the United Kingdom and the United States - all have above-average university entry rates compared to other OECD countries, despite having very high tuition fees. To be sure, this approach has its limits: if the cost of higher education is perceived as too expensive, individuals may choose not to pursue it, even if public subsidies to support them are available.

What's more, the high entry rates seen among some countries that charge no tuition fees may also be due to their highly-developed student financial support systems to cover living expenses, not just the absence of tuition fees. For instance, in Finland, Iceland, Norway and Sweden - four countries with above-average university entry rates - more than $55 \%$ of students benefit from public grants, public loans, or a combination of both. By contrast, countries with no tuition fees but less-developed student aid systems - such as Ireland and Mexico - have lower entry rates.

\section{... but the types of student aid that countries provide may be even more important.}

At the same time, the existence of a robust financial support system may not be enough to assure good outcomes for higher education students; the type of aid is also critical. Here again, approaches vary across OECD countries: more than one-third have systems that focus exclusively on providing grants, scholarships, or direct payments to universities in order to support students. Iceland provides only student loans, while the rest make a combination of grants and loans available.

Public subsidies for higher education, 2008

This figure shows the public subsidies for higher education given to households and other private entities as a percentage of total public expenditure on higher education, broken down by the type of subsidy.

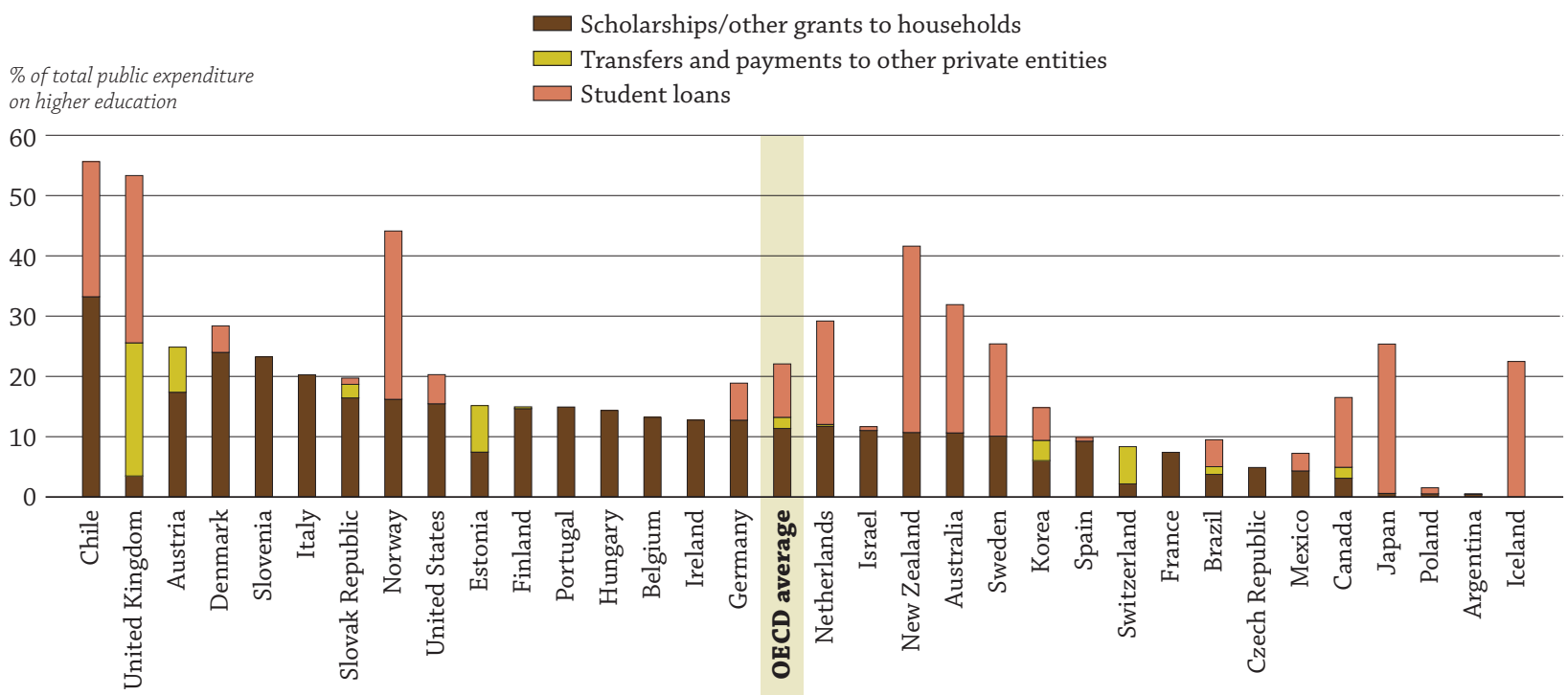

Source: Education at a Glance 2011: OECD Indicators, Indicator B5 (www.oecd.org/edu/eag2011). 


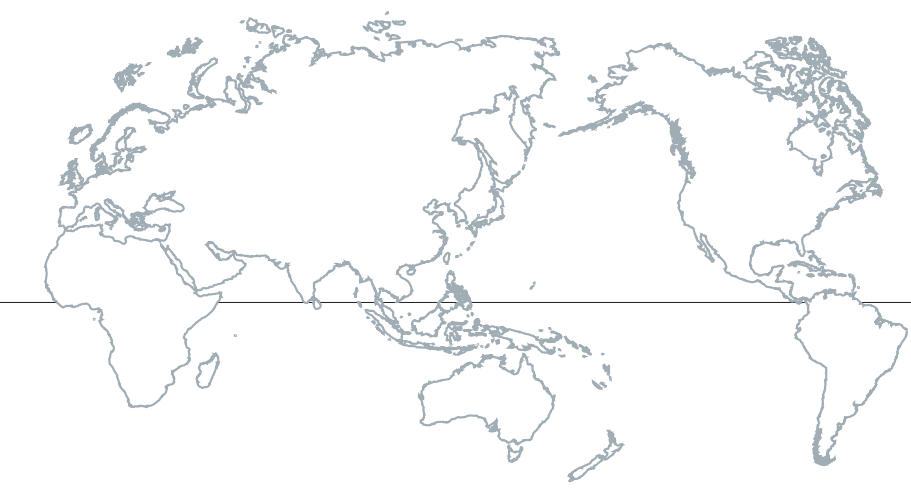

\begin{abstract}
OECD research suggests that student financial support systems that provide both loans with income-contingent repayments and means-tested grants not only promote access and equity at the front end of higher education, but also lead to better outcomes for students at the back end. For example, Australia and New Zealand have used this approach to mitigate the impact of high tuition fees, encourage disadvantaged students to enter higher education, and reduce the risks of high student loan indebtedness. Other OECD countries that offer meanstested grants and income-contingent loan repayments include Chile, the Netherlands, the United Kingdom, and the United States - although in some of these countries, income-contingent repayments are initiated at the borrower's request.
\end{abstract}

\title{
A well balanced mix between public and private funding is becoming increasingly important.
}

Increasingly, countries are also turning to other means to strike the right balance between keeping student charges reasonable and finding sufficient funding for their higher education systems. For example, some countries with highly subsidised higher education systems, such as Denmark and Sweden, increased tuition fees for non-European Union students in recent years, joining a long list of countries that charge higher rates for international students. At least 14 OECD member and partner countries differentiate tuition fees among fields of study to account for the higher cost of operating some academic programmes. Australia has even attempted to link the level of fees to labour-market opportunities by lowering tuition fees for fields with skills shortages, in order to attract more students.

As 2012 advances, further changes beckon. Later this year, tuition fees at some universities in England will triple as part of a government plan to stabilise university finances, and in the United States, leaders have introduced a plan to tie eligibility for student aid to institutions' success in keeping their prices down. In an era of booming enrolments and tightening belts, it won't be surprising if still more changes are on the horizon.

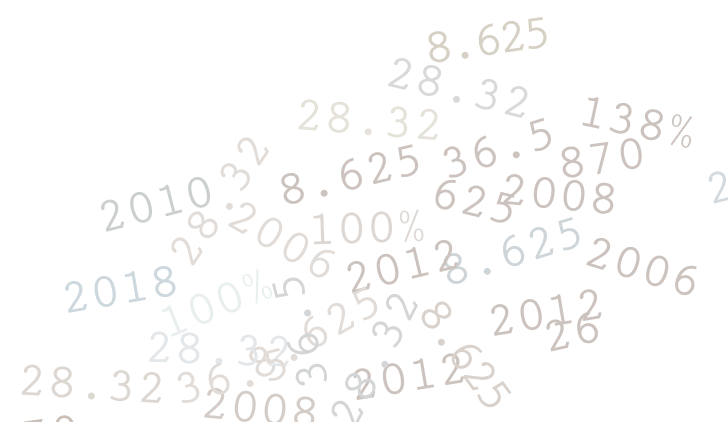

\begin{abstract}
The bottom line Higher education financing systems that charge a moderate level of tuition fees combined with student financial support systems that offer loans with income-contingent repayments and means-tested grants - may stand a better chance of promoting access, equity, completion, and positive outcomes for students.
\end{abstract}

\begin{tabular}{l|l|l|} 
Visit: & $\begin{array}{l}\text { See: } \\
\text { Education at a Glance 2011: }\end{array}$ & For more information, contact: \\
& J.D. LaRock (Jean-Daniel.LaRock@oecd.org)
\end{tabular}

Photo credit: @ Ghislain \& Marie David de Lossy/Cultura/Getty Images 